
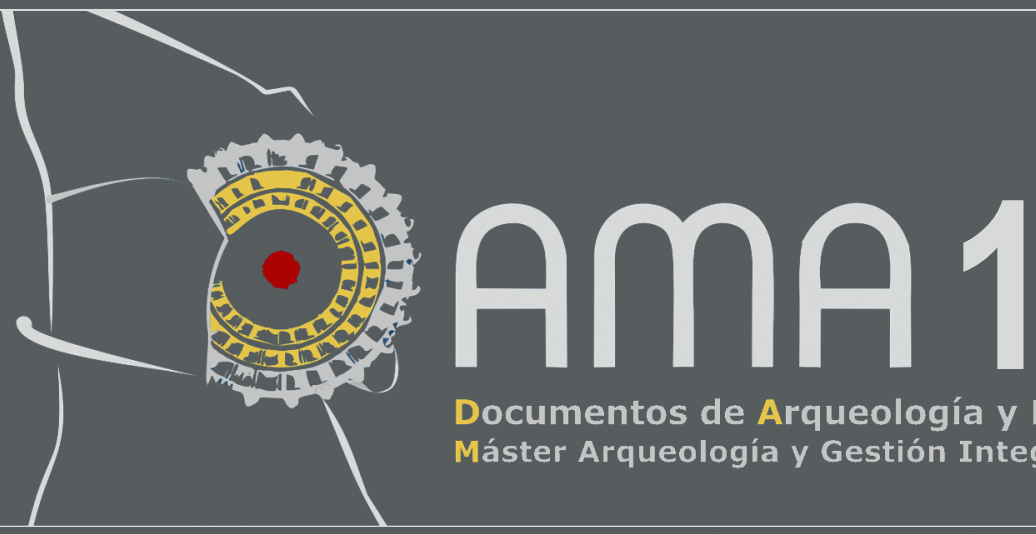

Documentos de Arqueología y Patrimonio Histórico

Máster Arqueología y Gestión Integral del Patrimonio de la Universidad de Alicante

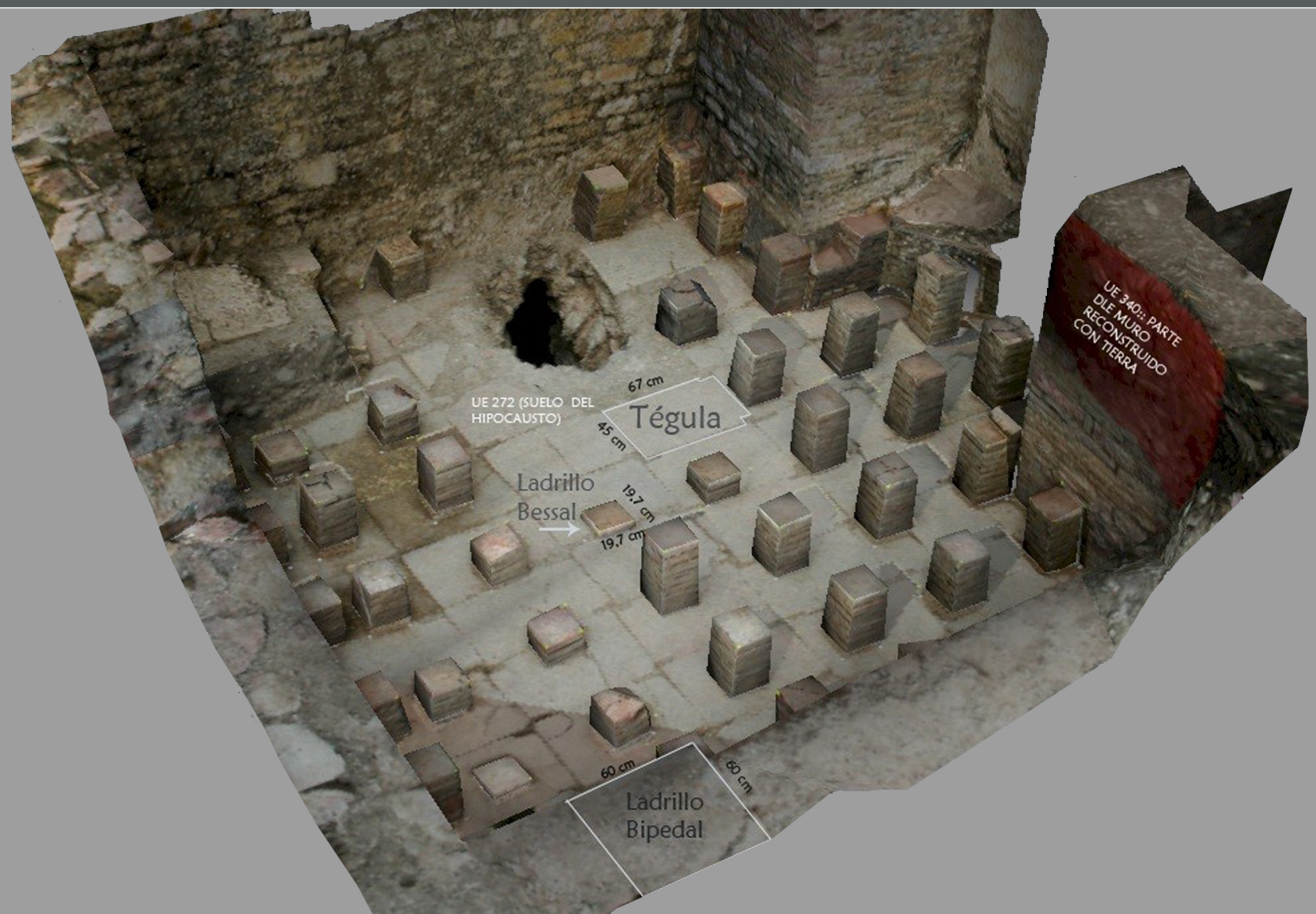

Documentos de Arqueología y Patrimonio Histórico Revista del Máster Universitario en Arqueología Profesional y Gestión integral del Patrimonio 



\section{DAMA 1}

\section{6}

DOCUMENTOS DE ARQUEOLOGÍA Y PATRIMONIO HISTÓRICO DEL MÁSTER UNIVERSITARIO EN ARQUEOLOGÍA PROFESIONAL Y GESTIÓN INTEGRAL DEL PATRIMONIO DE LA UNIVERSIDAD DE ALICANTE 


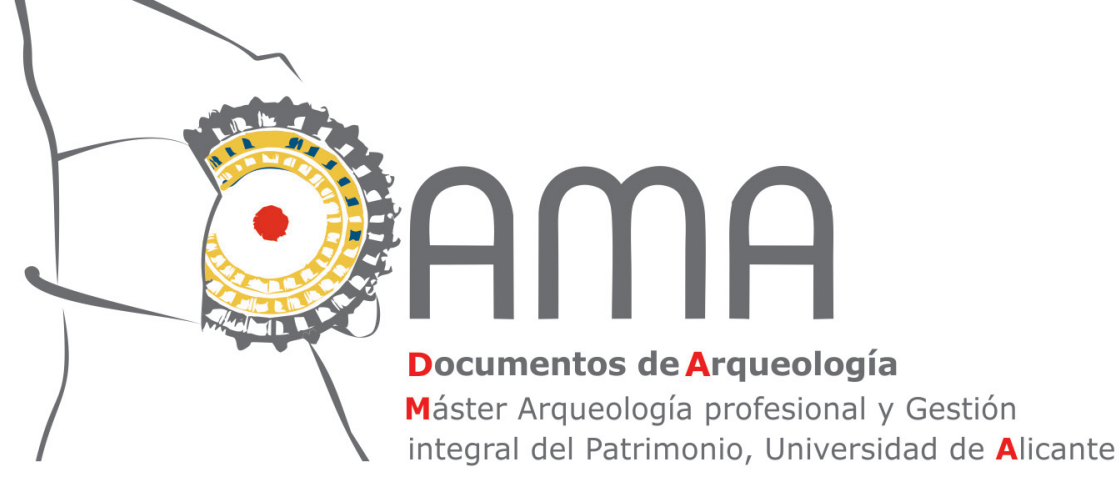

La revista electrónica DAMA. Documentos de Arqueología y Patrimonio Histórico surge como servicio para todos aquellos alumnos del Máster en Arqueología Profesional y Gestión Integral del Patrimonio de la Universidad de Alicante que se están iniciando en la investigación y cuya primera aportación a nuestra disciplina suele ser su Trabajo de Fin de Máster (TFM). Estos proyectos en muchos casos representan casi todo un curso de trabajo y esfuerzo, y con frecuencia quedan inéditos.

El objetivo de esta revista es ofrecer un medio que facilite la publicación de los resultados de sus TFM. La edición se presenta en versión digital y cuenta con su correspondiente ISSN. Se publica de forma anual en el sitio web de la Universidad de Alicante (http://web.ua.es/es/dama/) y en su repositorio (RUA). Los artículos publicados son descargables en formato PDF.

\section{Consejo de Redacción}

Directores (Coordinadores del Máster)

Carolina Doménech Belda

Fernando Prados Martínez

\section{Secretaria de Edición}

Julia Sarabia Bautista

\section{Vocales}

Los miembros de la Comisión Académica del Máster Universitario en Arqueología Profesional y Gestión del Patrimonio (http://dprha.ua.es/es/magip/comision-academica.html)

\section{Edita}

Máster Universitario en Arqueología Profesional y Gestión Integral del Patrimonio Departamento de Prehistoria, Arqueología, Historia Antigua, Filología Griega y Filología Latina

Facultad de Filosofía y Letras II

Universidad de Alicante

Ctra San Vicente del Raspeig s/n

E-03690 San Vicente del Raspeig (Alicante)

Web:http://dprha.ua.es

Teléfono: (+34) 965903663

Fax: (+34) 965903823

E-mail: revista.dama@ua.es

\section{ISSN}

$2530-2345$

\section{Portada}

Modelo fotogramétrico de un hypocaustum romano realizado por Ana Charquero 
EDITORIAL

Coordinación del máster

ENTREVISTA A SOLVEIG NORDSTRÖM: UNA MIRADA HACIA EL PASADO DE LA ESCUERA

Raúl Berenguer González ..

\section{ARQUEOLOGÍA Y MÉTODO}

EL ESTUDIO DE LOS MATERIALES CONSTRUCTIVOS DE TIERRA DEL CABEZO DEL POLOVAR (VILLENA, ALICANTE): APORTACIÓN A LAS FORMAS CONSTRUCTIVAS DE DOS PEQUEÑAS EDIFICACIONES CAMPESINAS DE LA EDAD DEL BRONCE EN EL LEVANTE PENINSULAR

María Pastor Quiles

VIVIENDAS POSTALAYÓTICAS: UNA APROXIMACIÓN A LOS ESPACIOS DOMÉSTICOS EN EL ARCHIPIÉLAGO BALEAR (550-123 ANE)

Octavio Torres Gomáriz

LAS FLOTAS DE GUARNICIÓN ROMANA EN LAS COSTAS DE HISPANIA A PARTIR DE LAS FUENTES EPIGRÁFICAS

Sergio Lledó Ramírez

UNA APROXIMACIÓN A LA RECONSTRUCCIÓN DEL PAISAJE HISTÓRICO: EL PROYECTO L'ALMISSERÀ Diana López Arroyo

NUEVAS PERSPECTIVAS PARA EL ESTUDIO ARQUEOLÓGICO DEL POBLAMIENTO RURAL MEDIEVAL EN ASPE (ALICANTE): HUERTAS Y ALQUERÍAS JUNTO AL RÍO TARAFA

Felipe Mejías López

ARQUEOLOGÍA DE LAS GUERRAS CARLISTAS

Iván Roldán Vergarachea

LA CERÁMICA DE USO ARQUITECTÓNICO EN NOVELDA: LA AZULEJERÍA DE FINALES DEL SIGLO XIX Y PRINCIPIOS DEL XX

Natalia Sala Pérez

PRÁCTICA Y USOS DE LA FOTOGRAMETRÍA DIGITAL EN ARQUEOLOGÍA

Ana $M^{a}$ Charquero Ballester.

\section{GESTIÓN Y PUESTA EN VALOR DEL PATRIMONIO}

ARQUEÓLOGOS CON DISCAPACIDAD. ARQUEOLOGÍA INCLUSIVA

Ana Samaniego Espinosa

"LES COVES DELS PESCADORS DE EL CAMPELLO": PROPUESTA DE RECUPERACIÓN, PUESTA EN VALOR Y USO PÚBLICO DE UN PATRIMONIO OLVIDADO

Ana Isabel Castro Carbonell .

LA COLONIA DE SANTA EULALIA. ESTUDIO Y PROPUESTA DE RECUPERACIÓN

Héctor de Arriba González

PROYECTO DE PUESTA EN VALOR DE LOS RESTOS DE LA GUERRA CIVIL EN LA CIUDAD DE ALICANTE

Leticia Victoria González Chouciño

ANTEPROYECTO MUSEOGRÁFICO DEL MUSEO DE HISTORIA DE SAX

Alberto Ochoa García

EL CONGRESO DE MÁSTER: UNA PROPUESTA DIDÁCTICA DEL MÁSTER DE ARQUEOLOGÍA DE LA UNIVERSIDAD DE ALICANTE

Ignasi Grau Mira, Sonia Gutiérrez Lloret, Carolina Doménech Belda, Julia Sarabia Bautista 



\title{
PRÁCTICA Y USOS DE LA FOTOGRAMETRÍA DIGITAL EN ARQUEOLOGÍA
}

\author{
Ana Mํㅡ Charquero Ballester
}

\section{Resumen}

Lo que aquí presentamos es una síntesis revisada y actualizada del trabajo de fin de máster que realizamos en 2010. Bajo la tutela del profesor Jaime Molina, el proyecto exploraba de forma práctica las posibilidades de integrar la fotogrametría digital como herramienta de registro habitual en arqueología. Se examinaba, desde la eficacia de la fotogrametría frente al dibujo tradicionalcontrastando tiempos de ejecución y valor informativo de cada técnica- hasta la idea de que la expresión tridimensional de una excavación arqueológica debería obtener su correspondencia en una documentación tridimensional. No se pasan por alto las posibilidades de utilizar la topografía como nexo de unión entre los "productos" fotogramétricos (ortofotos y modelos 3D) y las planimetrías arqueológicas, ni se obvian las ventajas que un registro fotogramétrico aportaría al calco de pinturas rupestres. Para evitar desactualizaciones se opta en esta revisión por la propuesta de procedimientos y pautas polivalentes, independientemente del programa, equipo informático o fotográfico que se vaya a utilizar. Todo es reflejo de la experiencia adquirida no sólo durante la realización de este proyecto, sino también de la continuación de esta línea de trabajo hasta la actualidad.

Palabras clave: dibujo, documentación, estratigrafía fotogrametría digital, metodología arqueológica.

\section{Abstract}

This paper is a revised and updated version of a master's dissertation presented in 2010 under the supervision of Prof. Jaime Molina. This project explores the possibilities of turning digital photogrammetry as a standard tool for recording archaeological stratigraphies. It is suggested that as a complex three-dimensional reality excavations should have a corresponding three-dimensional documentation. Efficiency, execution times and informational values are compared between traditional line drawing and digital photogrammetry. It also proposes topography as a connecting link between photogrammetry and archaeology and examines the adoption of photogrammetry to $3 \mathrm{D}$ rock art recording. In order to avoid outdated technology informations, this project focuses on methodological guidelines and workflows instead on specific software recommendations. It brings together the experienced gained not only during this project realization, but also during the current line of work continuation up to present.

Key words: drawing, documentation, digital photogrammetry stratigraphy, archaeological methodology. 
Corre en el año 1976. Antonio Almagro acaba de publicar un trabajo en el que experimenta con la fotogrametría como instrumento para la documentación arqueológica. No existen las cámaras de fotos digitales ni los ordenadores capaces de procesar decenas de imágenes, pero Almagro ya enumera en su trabajo las ventajas que atisba en una documentación fotogramétrica.

A lo largo de los 40 años que han pasado desde entonces, la cuestión de cómo adecuar la fotogrametría a la documentación arqueológica ha seguido vigente. Lo demuestran trabajos tanto de ámbito nacional (Almagro, 1992; Zoreda, 2006), como internacional (Koistinen, Latikka y Pöntien, 2001; De Reu, De Smedt, Herremans, Van Meirvenne, Laloo, De Clercq, 2014), y este mismo que ahora presentamos.

El motivo que justifica que se siga replanteando esta alianza entre arqueología y fotogrametría es que ni la primera ni la segunda -sobre todo esta última-- son las mismas de eran hace cuarenta años, ni siquiera de hace cuatro años, porque la tecnología en la que se basa la fotogrametría sigue una evolución constante e imparable.

Conscientes de este hecho, y del interés que tiene para la arqueología, en este trabajo vamos a intentar explicar en primer lugar cómo funciona la fotogrametría digital y cuáles son los procesos que hay tras ella. A continuación, cómo la fotogrametría permite transformar la documentación básica en ortofotos y modelos 3D. Y por último elegir de entre los protocolos y procedimientos que funcionan con la tecnología hacia la que ha derivado la fotogrametría aquellos que estimamos más adecuados para mejorar la documentación arqueológica, al margen de equipos o programas concretos.

\section{TÉCNICA Y HERRAMIENTAS}

\subsection{Fotogrametría digital automática}

El ser humano es de ubicarse en el espacio y de calcular las distancias entre objetos porque al observar, nuestros ojos registran dos imágenes algo distintas -desplazadas- de este objeto, imágenes que nuestro cerebro procesa para generar una imagen tridimensional. Es la visión estereoscópica. La fotogrametría se basa en este mismo hecho: si disponemos de dos -o más- fotografías de un mismo objeto tomadas desde puntos de vista significativamente diferentes, es posible obtener coordenadas tridimensionales de cualquier punto de ese objeto.

La restitución que nuestro cerebro hace inconscientemente, la fotogrametría la ha abordado de diversas maneras, en función de la fase de desarrollo en la que se encontrara: analógica, analítica o digital. En los años 90 nació la fotogrametría digital que empleaba fotografías digitales tratadas mediante técnicas de correlación y procesos automáticos que en sus primeros años requerían de estaciones fotogramétricas digitales; éstas están compuestas básicamente por un ordenador personal con dos monitores para la visón estereoscópica y estaciones de trabajo propias para ejecutar esos softwares de fotogrametría, como UNIX o SilicON Graphics.

A principios del siglo XXI la fotogrametría digital se ha extendido fuera de este ámbito altamente especializado y se ha ido haciendo accesible a un público mucho más amplio. Y ello gracias a que los avances de todo tipo han permitido procesar imágenes digitales tomadas con cámaras de uso doméstico -necesariamente calibradas- en softwares que ejecutables en un ordenador personal, capaz también de restituir las geometrías tridimensionales. Ello ha abierto las posibilidades de esta tecnología a un público mucho más amplio. 
El primer software de restitución fotogramétrica en soporte comercial fue Photomodeler, creado en 1999 por la empresa EOS SYSTEM. Fue un programa pionero que requería de la intervención del usuario, quien debía calibrar la cámara para que el software conociera los parámetros internos de la misma. Una vez realizadas las fotografías e introducidas en el software, el usuario tenía que marcar manualmente 6 puntos de control homólogos, identificables en al menos dos fotografías.

Con estos datos el software recurría al principio de la triangulación, según el cual, al tomar dos fotografías de un mismo objeto desde al menos dos posiciones, se puede trazar la trayectoria de los "haces de luz" que van desde el centro del objetivo de cada cámara hacia un punto de interés marcado en el objeto. El punto donde estos haces de naturaleza óptica se cruzan matemáticamente son las coordenadas tridimensionales de ese punto de interés, y vendrán determinadas por el centro del objetivo de cada cámara y el punto marcado en el objeto. Mediante la repetición de este proceso se determinaban manualmente los puntos que definían la geometría del objeto. El usuario tenía que unir estos puntos manualmente para crear polígonos que conformaban la geometría del modelo 3D.

Era un proceso largo y que requería cierta habilidad, que no se podía aplicar a superficies con relieve irregular, ya que era imposible unir manualmente miles de polígonos que la reprodujeran. Por eso, en una versión posterior, Photomodeler Scanner empezó a incorporar unos algoritmos basados en la correspondencia de imágenes (Imaged Based modelling, IBM), que en cada estéreopar de fotografías comparaba automáticamente pixel a pixel, en busca de correspondencias que, al encontrarlas, quedaban convertidas en un punto tridimensional de la nube de puntos.

Era la combinación de estéreo-pares convergentes la clave del proceso, ya que la convergencia proporcionaba la información necesaria sobre la ubicación 3D de los puntos de control u homólogos que permitían reconstruir la estructura básica del objeto; y los estéreo-pares generaban las nubes de puntos que reproducían los relieves de su superficie.

Comparado con la fotogrametría digital de restituidores, el proceso es sencillo, sin embargo, la ubicación de puntos manuales, y sobre todo, las necesidades derivadas de la separación obligada entre estéreo-pares, llevaba muchas veces a una toma de fotos un tanto rígida o limitada. El proceso concluía al transferir a dos de esos puntos de control la distancia real entre ellos, medida sobre el objeto o la escena. Así, el modelo quedaba escalado.

No pasaron más que unos pocos años cuando en 2006 salió al mercado el software de restitución Photoscan, esta vez de la mano de la empresa rusa Agisoft. Superaba al anterior en velocidad, precisión, resultados y estabilidad, pero la diferencia más significativa era que incorporaba de manera innovadora la tecnología de visión por computadora que le permitía realizar una detección y correlación de imágenes "inteligente". No fue el único, pero sí el más destacado entre los softwares comerciales del momento en incorporar la tecnología Structure from Motion (SFM) o estructura del movimiento.

Es ésta una tecnología que procede del ámbito de la visión por computador y que restituye la geometría tridimensional de una escena a partir de imágenes procedentes de un sensor en movimiento. Y además, lo hace resolviendo de forma simultánea y automática la geometría de la escena y las posiciones y orientaciones de las cámaras sin necesidad de especificar manualmente una serie de puntos de control. Esto significa que a partir de ese momento es posible correlacionar imágenes automática y eficazmente y situar todos los píxeles de las mismas en un espacio tridimensional, creando geometrías con miles de polígonos. El proceso se ha simplificado considerablemente, al tiempo que nuevos softwares y aplicaciones facilitan su gestión, lo que permite que llegue a un público cada vez más amplio. 


\subsection{Herramientas en fotogrametría digital automática}

Para realizar proyectos de fotogrametría digital automatizada, las herramientas necesarias son un software de restitución, un PC y una cámara de fotos, con un posible sistema de elevación.

\subsubsection{Softwares de restitución 3D}

La variedad de softwares que utilizan principios de fotogrametría y la tecnología de la visión por ordenador es cada vez más amplia ${ }^{1}$. Ofrecemos aquí una visión de general de los tipos de softwares que actualmente existen para que el usuario pueda elegir en función de las necesidades del proyecto que vaya a realizar.

Los softwares de uso más extendido son comerciales o de pago, como Photmodeler y Photoscan. Son softwares que se instalan en nuestros equipos y que procesan las imágenes en tiempo real utilizando los recursos del ordenador, es decir, softwares de escritorio. El número de imágenes que son capaces de procesar está en función de las capacidades del PC en que se ejecute, y de esto dependerá la calidad del modelo 3D. Reality Capture, 3DF Zephir o Pix4D, son otros softwares comerciales de fotogrametría, este último específico para drones. Todos ellos suelen permitir al usuario amplias opciones de configuración del modelado y una mayor intervención en cada uno de los pasos del proceso. Y ofrecen también una gran variedad de formatos de salida del modelo 3D.

Una alternativa a estos softwares comerciales son los softwares libres con servidores remotos, como Arc3D, Photosynth de Microsoft o 123D Catch de Autodesk. En estos casos, sin necesidad de instalar el software en el equipo propio, el usuario sube sus fotos a un servidor remoto que le devuelve un modelo 3D. El procesado en la nube o cloud computing cambia la necesidad de un potente PC capaz de realizar estos procesos, por una potente conexión a internet. La tecnología SfM de estos softwares permite una toma de fotos no estructurada. A cambio, el usuario no tiene acceso a la configuración del modelado, únicamente puede descargar el modelo en un formato ya totalmente texturizado (.obj) y, en el caso de 123DCatch, los derechos sobre este modelo los adquiere Autodesk.

En el otro extremo se encuentran los softwares de restitución 3D libres y de código abierto. Son unas herramientas con mucho potencial que permiten al usuario no solo el acceso a los datos y al proceso de trabajo, sino también a sus códigos de programación. Suelen ser softwares de escritorio, multiplataforma, con opción a ser ejecutados desde línea de comandos o mediante interfaz gráfica. Generan nubes de puntos 3D que normalmente han de ser visualizadas y convertidas en malla en otro software. Entre ellos se encuentran Visual SfM, el francés Micmac-Apero y Python Photogrametry Tool, uno de los más extendidos, que usa el lenguaje de programación Python para ejecutar los algoritmos de la tecnología $S f M$.

La elección del tipo de software dependerá del objetivo y de las necesidades del usuario.

\subsubsection{El equipo informático}

Los requisitos que harán que un equipo informático sea más o menos adecuado para realizar proyectos fotogramétricos estarán en función del tipo de software que elijamos: de escritorio o que procese los datos en la nube. En el caso de elegir un software de escritorio, los propios creadores establecerán los requisitos mínimos del equipo informático. Con todo, las pautas generales para gestionar y trabajar con modelos 3D serán las de contar con un buen procesador para gestionar los datos, una memoria RAM ampliable y una tarjeta gráfica que tenga potencia suficiente como para

1 Una relación bastante completa de softwares de fotogrametría se puede encontrar en la siguiente dirección: https:// en.wikipedia.org/wiki/Comparison of photogrammetry software 
visualizar correctamente y con rapidez los datos generados. El otro factor a tener en cuenta será la calidad y por tanto el peso de las imágenes que vayamos a procesar, lo que a su vez estará en función del tipo y de la calidad del dispositivo fotográfico que utilicemos.

\subsection{3. ¿Qué cámara de fotos utilizar?}

La importancia de las fotografías para restituciones 3D es fundamental. Por ello aunque se pueden realizar modelos 3D con las imágenes digitales de la mayoría de dispositivos actuales -incluso a partir de las fotos de las cámaras GoPro-, para un proyecto fotogramétrico de calidad se recomienda el uso de una cámara réflex digital, teniendo en cuenta las siguientes observaciones:

- $\quad$ No es necesario comenzar con la mejor cámara del mercado. Se puede comenzar con una de gama baja, mucho más económica, e ir subiendo a medida que los conocimientos en fotografía van aumentando. Hay que tener en cuenta detalles aparentemente nimios, como por ejemplo que la pantalla sea abatible.

- La calidad y configuración del objetivo es de la mayor importancia. Para fotogrametría lo mejor son objetivos luminosos, con amplia apertura de diafragma, estabilizador y distancia focal fija de $50 \mathrm{~mm}$ o, mejor, de $35 \mathrm{~mm}$.

- La cantidad de megapíxeles de la cámara debe ser congruente con el equipo informático o el software en el que vayamos a procesar las imágenes y, sobre todo, con las necesidades de precisión reales de nuestros proyectos.

- $\quad$ Más que la cantidad de megapíxeles importa el tamaño del píxel, que depende del sensor de la cámara. Un buen sensor captará píxeles mayores y, por tanto, píxeles que muestren más detalle en las zonas de la foto de iluminación difícil.

\subsubsection{Sistemas de elevación de la cámara}

Un trípode es muy recomendable en exteriores y necesario si la toma de fotos tiene lugar en un interior. Se recomienda que tenga cabezal de bola, porque permite un control más versátil y resulta muy útil en fotogrametría.

Y cuando se necesite elevar la cámara, se puede recurrir a una pértiga telescópica, al final de la cual se sitúa la cámara de fotos. Hay que conectarla a un dispositivo móvil (pantalla LCD, tablet o smartphone, para poder ver en tiempo real la imagen que se obtiene a través del visor de la cámara. Y tener en cuenta que si la toma es a plena luz del día no siempre resultad fácil ver con claridad en estas pantallas. La cámara hay que dispararla mediante control remoto.

\section{EL PROYECTO FOTOGRAMÉTRICO}

\subsection{Planificar la toma de fotos}

Hemos visto que gracias a la tecnología $S f M$, la toma de fotografías ya no es un proceso tan rígido. Sin embargo, del éxito de la toma de fotos, dependerá el éxito del proyecto. Será necesario hacer una planificación personalizada para cada escenario. Resulta muy útil hacer un croquis previo con la escena y las posiciones de las cámaras para la toma de fotos, que en función del elemento a documentar podrán ser:

- fotografías convergentes entre sí con un alto grado de solape en torno al elemento a modelar, normalmente, objetos aislados o de espacios dentro de los que estemos inmersos nosotros mismos, como habitaciones. 
- fotografías paralelas con solapes laterales y superiores e inferiores, a modo de mosaico de fotografías. Es el modo que usaremos si queremos fotografías de superficies planas (Fig. 1).

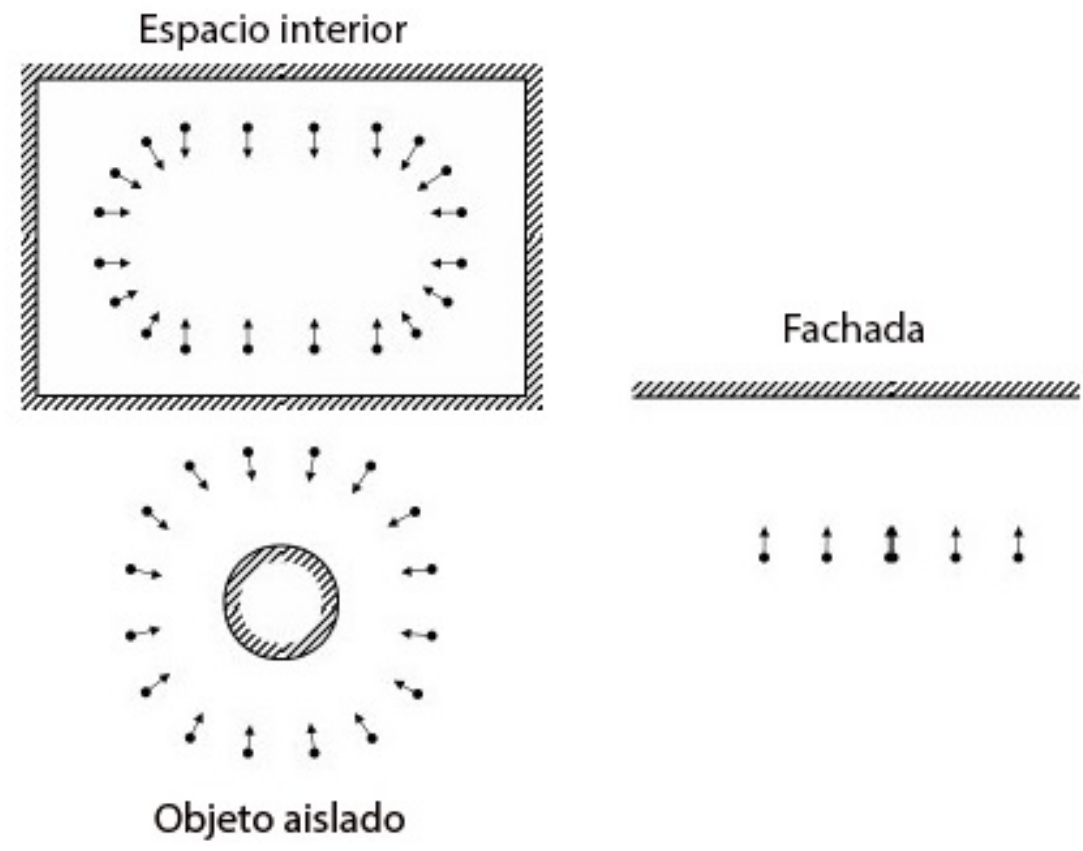

Fig. 1. Disposición de las cámaras en función de los distintos escenarios y de las características del elemento a documentar (Agisoft PhotoScan User Manual, p. 6).

En algunos casos, será conveniente combinar ambos modos. Además, aconsejamos evitar en las fotografías los grandes contrastes de luces y sombras, ya que la restitución de esas áreas presentará problemas. Intentaremos que en la fotografía, el objeto que nos interese ocupe la mayor parte posible de la escena, y no lo moveremos, sino que seremos nosotros lo que nos movamos en torno a él, siguiendo un orden en el desplazamiento.

\subsection{Configurar la cámara de fotos.}

Aunque no será necesario calibrar la cámara de fotos, una configuración adecuada de la misma favorecerá unos resultados favorables. A continuación, algunas recomendaciones:

- $\quad$ No es necesario configurar de salida de la cámara en RAW, ya que se ha comprobado que un formato JPG de alta calidad no proporciona unos resultados visiblemente peores.

- Utilizar preferiblemente un objetivo de distancia focal fija (35 o $50 \mathrm{~mm}$ ). En caso de recurrir a un objetivo zoom, mantener la misma distancia focal en todas las fotos.

- Utilizar, en la medida de lo posible, el modo manual de la cámara, así como el enfoque manual.

- Evitar las fotos con zonas desenfocadas; producirán error al modelarlas. Para evitarlo, aseguraremos una buena profundidad de campo cerrando el diafragma (f/16- $f / 22$ ).

- $\quad$ Evitar que la foto salga movida -especialmente si estamos utilizando una pértiga-mediante el uso de una velocidad corta (1/125 o 1/160). 
- Usar una velocidad ISO baja, evitará el grano, y por tanto, zonas de difícil restitución.

\subsection{Tomar una medida de referencia}

Tomaremos, en la escena real, la medida de una distancia entre dos puntos marcados por dianas o que podamos distinguir fácilmente en las fotografías. Procuraremos medir una distancia acorde con el tamaño de la escena que queramos escalar.

\subsection{Antes y después de la restitución 3D}

Tras volcar las imágenes al ordenador, si es necesario, podemos corregir u optimizar el acabado de nuestras fotografías en algún software de retoque fotográfico, y corregir niveles de contraste, brillo o exposición. Aconsejamos comprobar la viabilidad del proyecto modelando primero las fotos en baja calidad, y una vez asegurado el éxito del modelado de ese conjunto de imágenes, aumentar la calidad. Una vez realizada la restitución, y en función del software que utilicemos, habremos de tener claro que podemos obtener los siguientes "productos" digitales:

- Nube de puntos tridimensional con información volumétrica y colorimétrica de la escena o el objeto. La unión de los puntos de esa malla producirá una nube de polígonos. La nube de puntos puede tener varios formatos (LAS, E57, TXT, XYZ, LAZ, FWS, FLS, XYB, PLY, PTS, PTX) y podrá ser visualizada y procesadas en distintos softwares. Es el producto del modelado en bruto, el más ligero y la base de los modelos 3D, por lo que nos conviene tener acceso a la misma.

- Malla poligonal texturizada o no. Los formatos de mallas más habituales son DAE, 3DS, FBX, PLY, OBJ, STL, SVG.,...) La malla es una entidad cuya morfología se puede editar recortándola, o haciendo una retopología de su superficie. La textura de la malla puede ser modificada, pintada, etc.

- $\quad$ Ortofoto es un archivo de imagen (JPG o TIFF) que obtendremos de la vista del modelo o de la escena que seleccionemos y que será una proyección ortogonal de esa vista, con una escala uniforme, y por tanto, susceptible de ser utilizada como un mapa, de la que podremos obtener directamente calcos digitales.

La recomendación general a la hora de emprender un proyecto fotogramétrico es empezar por proyectos sencillos de pocas fotos e ir aumentando en complejidad a medida que nos vayamos familiarizando con la técnica.

\section{FOTOGRAMETRÍA DIGITAL Y ARQUEOLOGÍA}

El rápido desarrollo de la fotogrametría digital proporciona, como hemos visto, productos digitales con potencial. Aunque el planteamiento original de este trabajo fue si la fotogrametría digital podía ser una alternativa eficaz al dibujo arqueológico, la continuación de esta línea de trabajo nos lleva a modificarlo ligeramente por la cuestión de si la fotogrametría digital puede llegar a integrarse completamente como técnica para un registro arqueológico integral.

Para analizar la cuestión se hicieron dos pruebas experimentales; la primera consistió en valorar distintos aspectos de ambas técnicas de documentación: dibujo y fotogrametría. La segunda giró en torno a ver si una documentación fotogramétrica tridimensional integral de la excavación era practicable a nivel metodológico. 


\subsection{Dibujo Arqueológico 2.0 o la ortofoto como complemento del dibujo arqueológico}

La herramienta fundamental de un arqueólogo para documentar es el dibujo. A través de él consigue recoger y aislar la información que considera relevante, ya que el valor del dibujo reside justamente en que no es una imagen de la realidad, sino una representación de la misma (Carandini, 1997, p. 116). Estando de acuerdo con estos enunciados, creemos, sin embargo, que una documentación de base fotogramétrica podría llegar a ser más eficaz y, además, ampliar el contenido informativo.

El elemento elegido para realizar un análisis comparativo entre ambos tipos de documentación fue uno de los alzados de un área septentrional de la villa de Rufione situada en Toccioli, Giano dell'Umbria (Italia). Se trataba de un arco roto y colmatado que habría formado parte de las instalaciones termales de la villa.

Dos arqueólogos con experiencia como dibujantes realizaron el dibujo a mano sobre papel milimetrado. Este dibujo fue digitalizado y sus líneas fueron repasadas en un software de dibujo vectorial (AutoCad) y en Photoshop. Posteriormente se documentó el área mediante fotogrametría; se colocaron dianas y se fotografió el alzado. Se hizo la restitución en el software de fotogrametría

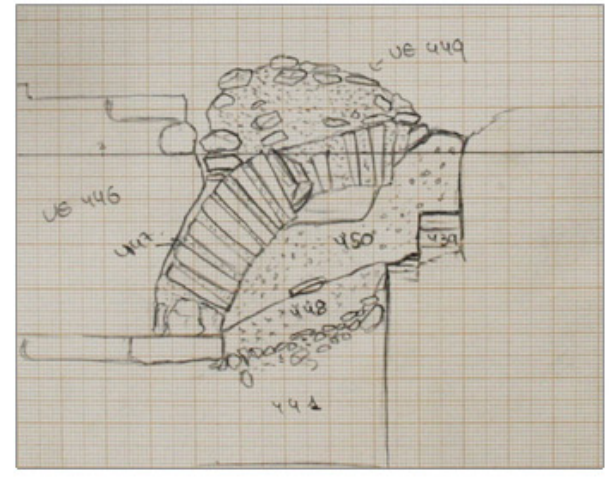

Dibujo a mano.

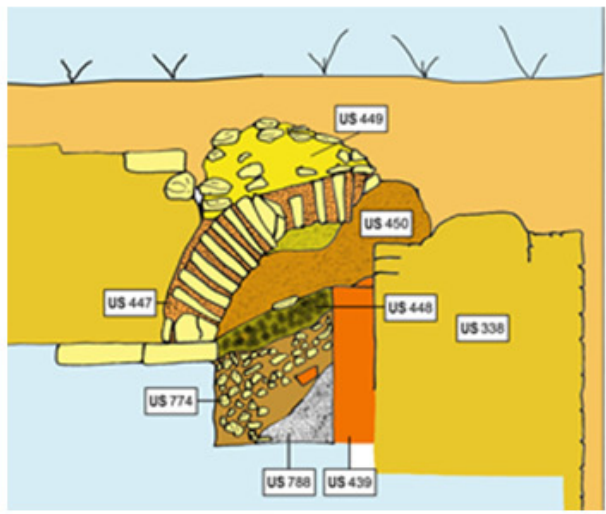

Dibujo en Photoshop a partir del dibujo hecho a mano.

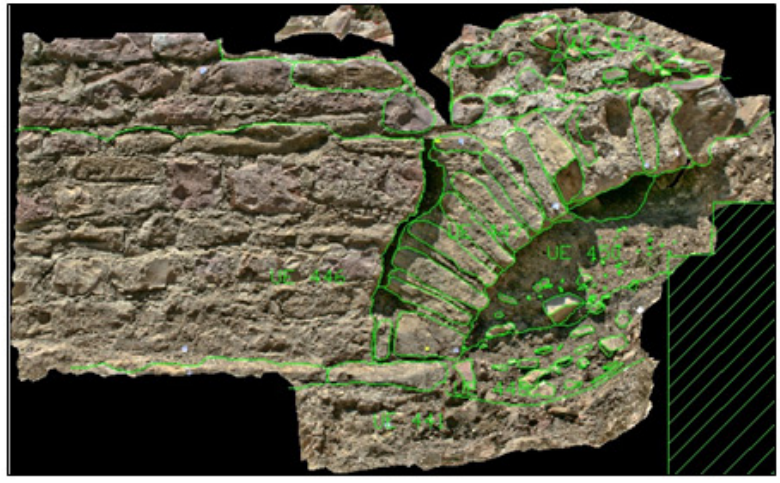

Dibujo sobre la ortofoto.

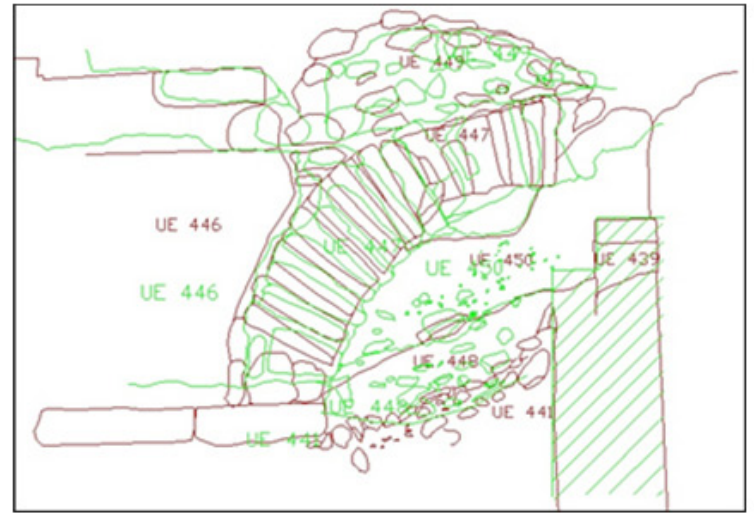

Comparación del error entre el calco obtenido mediante el dibujo a mano (rojo) y el calco obtenido de la ortofoto.

Fig. 2. Distintos resultados del mimso elemento documentado con ambas técnicas. Desde arriba a la izquierda y en el sentido de las agujas del reloj; dibujo a mano sobre papel milimetrado, dibujo en AutoCad sobre la ortofoto, comparacion de los dos calcos anteriores y digitalización en Photoshop del dibujo a mano. 
Photomodeler Scanner y se obtuvo una ortofoto, que insertada en AutoCad sirvió de base para el dibujo vectorial de los elementos (Fig. 2).

Los parámetros comparados fueron los siguientes (Fig. 3 tabla)

\begin{tabular}{|l|l|l|}
\hline & Dibujo a mano & fotogrametría \\
\hline Tiempos en campo & $69 \mathrm{~min}$ & $17 \mathrm{~min}$ \\
\hline Tiempos en laboratorio & $50 \mathrm{~min}$ (calco en autocad) & $65 \mathrm{~min}$ \\
& & $\begin{array}{l}(23 \mathrm{~min} \text { restitución de la } \\
\text { ortofoto y 42 min calco en } \\
\text { AutoCad) }\end{array}$ \\
\hline Total tiempos & & 82 min \\
\hline Costes & 119 min & Arqueólogo fotogrametrista \\
\hline Documentación & Arqueólogo dibujante & Ortofoto y calco sin error \\
\hline
\end{tabular}

Fig. 3. Tabla con los parámetros utilizados en la comparación entre el dibujo a mano y la documentación fotogramétrica.

Las conclusiones tras la prueba fueron las siguientes:

- La fotogrametría ahorra tiempo en campo, que es donde puede haber más presión por avanzar. A cambio, en el laboratorio requiere el tiempo añadido de la restitución. A pesar de ello, la fotogrametría es en conjunto más rápida. Con la experiencia hemos comprobado que cuanto mayor es el área a documentar o mayor densidad de restos contiene, más destaca la efectividad de la misma frente al dibujo manual.

- $\quad$ En cuanto a los costes, la inversión en herramientas es mínima, y los del profesional encargado de realizarla no habrían de suponer un gasto extra si, al igual que en dibujo, se proporciona a los arqueólogos una formación en fotogrametría.

- La documentación fotogramétrica, al ser de base fotográfica, aporta una información en color, con un alto grado de detalle, con calidad métrica. El dibujo vectorial incluirá inevitablemente cierto grado de error en alguna de las proporciones o distancias entre los elementos. Además, la ortofoto proporciona una base documental objetiva, revisable y abierta a futuras reinterpretaciones. El calco puede visualizarse sin el fondo de la ortofoto, proporcionando la representación gráfica esquemática útil para el arqueólogo.

El dibujo realizado a partir de la observación directa de la realidad no puede ni debe ser sustituido, pero una base documental fotogramétrica puede agilizar el proceso, proporcionar información más precisa y detallada y servir de base para, el dibujo, que como señala Carandini, consiste en filtrar una idea (unidad de información) en una imagen (Carandini, 1997, p. 116). 


\subsection{Registro arqueológico tridimensional global}

Desde un punto de vista técnico, la ortofoto -que es el producto más común de la fotogrametría- es capaz de complementar y optimizar el dibujo arqueológico. El siguiente paso lógico es analizar si a nivel metodológico se pueden combinar documentación gráfica arqueológica -estrechamente vinculada al método de excavación- y documentación fotogramétrica, y estudiar si se puede introducir una base documental íntegramente tridimensional. Para ello, analizamos el papel del dibujo arqueológico bidimensional para documentar una realidad tridimensional que viene moldeada por el propio método de excavación.

\subsection{Las necesidades documentales en Arqueología}

La forma de documentación arqueológica está intrínsecamente ligada al método de excavación; el actual método de excavación Harris, en área abierta y siguiendo la estratigrafía, viene acompañado de un registro que plasma sobre el papel la retirada secuencial de estratos, documentando la extensión y disposición espacial de éstos, así como y sus relaciones, para darles un significado temporal.

La documentación arqueológica basada en el dibujo se esfuerza por buscar la forma de representar tanto las entidades estratigráficas, como sus relaciones a partir de plantas, alzados y secciones. "Las plantas de estrato simple registran los contornos horizontales de los estratos, y las cotas recogen las dimensiones verticales" (Harris, 1991, p. 153), pero han de ser completadas por las secciones, que registran no sólo la dimensión vertical del yacimiento, sino también los contornos de las superficies, las relaciones estratigráficas y las secuencias (Carandini, 1997, p. 121).

Sin embargo, las secciones son una muestra muy selectiva de todo el conjunto, porque solo ilustran la complejidad de la estratigrafía a lo largo de un determinado plano vertical que puede no tener nada que ver con el siguiente plano vertical (Carandini, 1997, p. 108). 0 lo que es lo mismo "Las secciones y las plantas seleccionan siempre un aspecto diacrónico o sincrónico de la realidad que se quiere
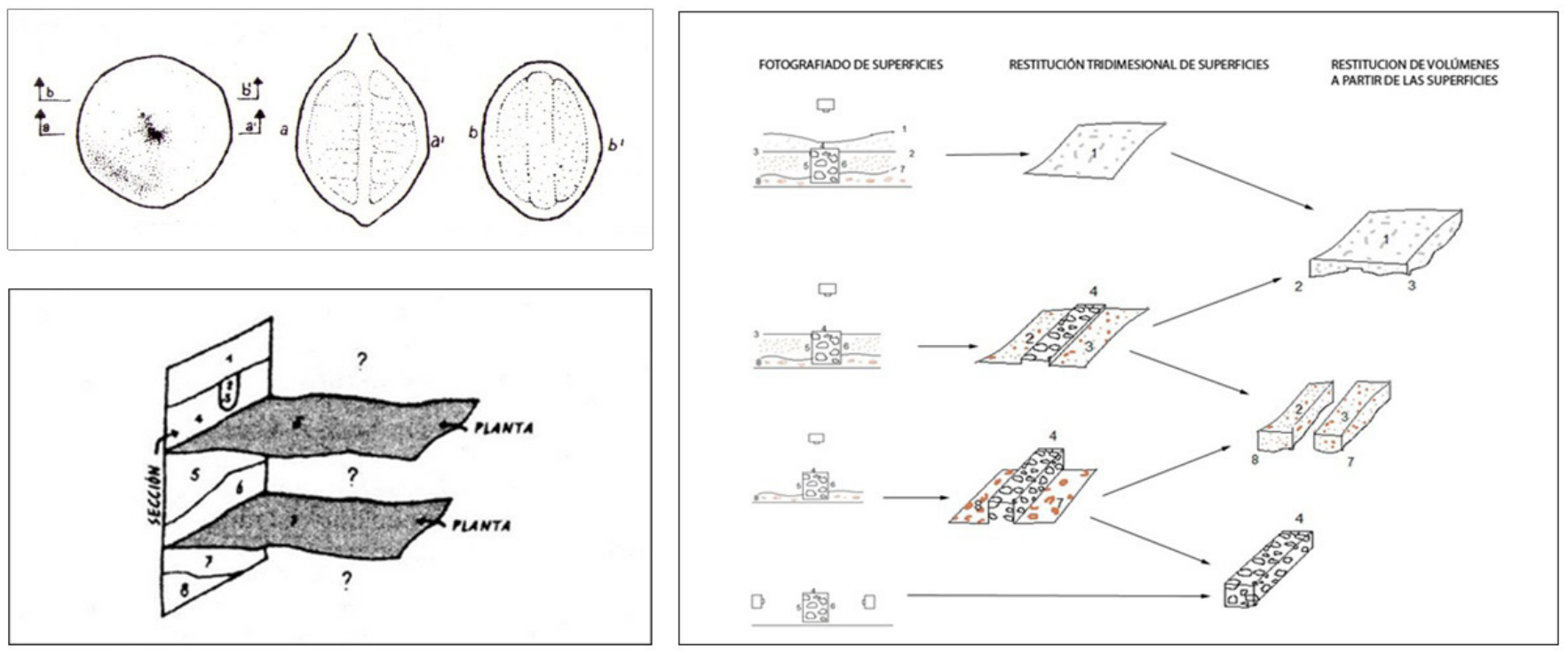

Fig. 4. Arriba a la izquierda, ejemplo de cómo dos secciones paralelas ofrecen imágenes diversas entre sí (Carandini, 1997, p.108). Abajo a la izquierda, cómo las secciones dan información diacrónica y las plantas, sincrónica, dejando lagunas de información (Carandini, 1997, 83). A la derecha, proceso de fotografiado de superficies y restitución $3 D$ del volúmen a partir de éstas. 
representar y no permiten una visión global de todas las unidades estratigráficas, sus relaciones y correlaciones (...). (Carandini, 1997, p. 83) (Fig. 4). Esta insatisfacción deriva de que la plasmación bidimensional de una realidad tridimensional tiene sus limitaciones lógicas.

\subsection{Teoría de una documentación 3D de la estratigrafía}

Para plantear una documentación tridimensional de la excavación, hay que documentar las unidades que la componen, que son los estratos. Los estratos son películas intangibles en las que reside gran parte del valor espacio-temporal implícito en la estratificación y que tan sólo se pueden reconocer y documentar (Carandini, 1997, p. 76). Un estrato está formado por una superficie, un contorno y un relieve (Harris, 1991), es decir, que son entidades tridimensionales de las que una copia virtual tridimensional recogería su comportamiento en todas sus vertientes y respecto a los demás. Además de los estratos positivos, las acciones negativas (agujeros, acciones de destrucción), también quedan reflejadas en superficies en sí mismas (interfaces negativas) (Carandini, 1997, p. 73), que también serían fácilmente captadas por la fotogrametría. De hecho, sería suficiente con la documentación de estas superficies, puesto que "el volumen de un estrato se halla comprendido entre su superficie superior y la superficie superior de los estratos que éste cubre físicamente"(Carandini, 1997, p. 73), de modo que reproduciendo la disposición espacial exacta de las superficies en 3D recompondríamos el volumen del yacimiento (Fig. 4).

\subsection{Protocolo de actuación}

Aunque van en aumento, son escasos los ejemplos del uso de la fotogrametría para documentar completamente una excavación arqueológica (Caballero Zoreda, 1996; Barceló et al., 2003, Cattani et al., 2004; Fiorini, 2008; De Reu et al., 2014). Dado que no existen unas pautas metodológicas para realizar este tipo de documentación en intervenciones, vamos a proponer un protocolo de actuación en campo integrado en la dinámica de excavación:

a) Planificación sobre el terreno

El objetivo será, conocer la extensión total a documentar y planificar in situ la toma de fotografías, y una posible división de la superficie, utilizando estructuras murarias o varillas como elementos divisores, que además nos puedan servir de soporte para ubicar algunos puntos de apoyo.

b) Colocación de dianas

Será fundamental establecer un sistema de puntos de control que luego nos permitan relacionar superficies documentadas tanto en extensión -si hemos dividido el área de la excavación- como en profundidad tras la retirada de estratos. Las características de la intervención establecerán si una serie de puntos fijos numerados, colocados sobre algún soporte que vaya a permanecer inalterable a lo largo de la intervención, será suficiente o si además, habrá que colocar una serie de puntos de apoyo "efímeros" sobre los estratos, que tras ser topografiados y fotografiados serán retirados para continuar con la excavación. Podremos colocar, además, dos dianas diferenciadas en forma o color, que sistemáticamente tengan una orientación norte-sur y marquen una distancia fija de $1 \mathrm{~m}$.

c) Toma de datos topográficos

Aprovechando la toma de datos topográficos común en las intervenciones, documentaremos los puntos de control fijos. La documentación de los puntos efímeros, en el caso de haberlos colocado, podrá realizarse a la vez que la toma de cotas. La información de ambos tipos de puntos quedará reflejada en la ficha fotogramétrica. 


\section{d) Toma de fotografías}

Siguiendo la planificación de tomas que hayamos diseñado previamente, procederemos a fotografiar las superficies a documentar, bien de forma manual, bien con ayuda de un trípode o de una pértiga. Será conveniente, como en las fotos de documentación, utilizar algún tipo de pizarra que identifique la unidad fotografiada.

Como vemos, la toma de datos fotogramétricos se sirve de la topografía y de la fotografía, que son herramientas profundamente integradas en la metodología arqueológica y que, por tanto, no rompen su dinámica; la toma de fotos sustituye y reduce el tiempo de dibujo y los datos de la topografía, habitualmente ya incluida en el ritmo de excavación, se reflejan simultáneamente en la ficha fotogramétrica. Por tanto, todos son pasos fácilmente integrables en la metodología documental arqueológica.

\subsection{Propuesta de ficha fotogramétrica}

Inspirada en las fichas de documentación arqueológica, el objetivo de esta ficha (Fig. 5) es sistematizar la recogida de información en campo e interrelacionar la información topográfica y fotogramétrica.

Tras las casillas correspondientes a la identificación de la intervención y del elemento documentado, le sigue una tabla dedicada a identificar las fotos hechas para la restitución fotogramétrica y su distancia focal.

A continuación, sigue el croquis y el listado que ha de recoger la relación de los puntos acotados; el croquis habrá de reflejar la ubicación de cada punto de control en la foto y el número que lo identifique y que servirá para relacionarlo con la información topográfica contenida en la tabla numérica de la derecha, que además de la cota, indicará la UE a la que pertenece cada punto de control. La distinción entre puntos de control fijos, efímeros y los que marquen orientación y distancia, podrá hacerse mediante distintos símbolos gráficos o asignándoles numeraciones distintas (decenas, centenas, etc.).

FICHA DE DOCUMENACIÓN FOTOGRAMÉTRICA

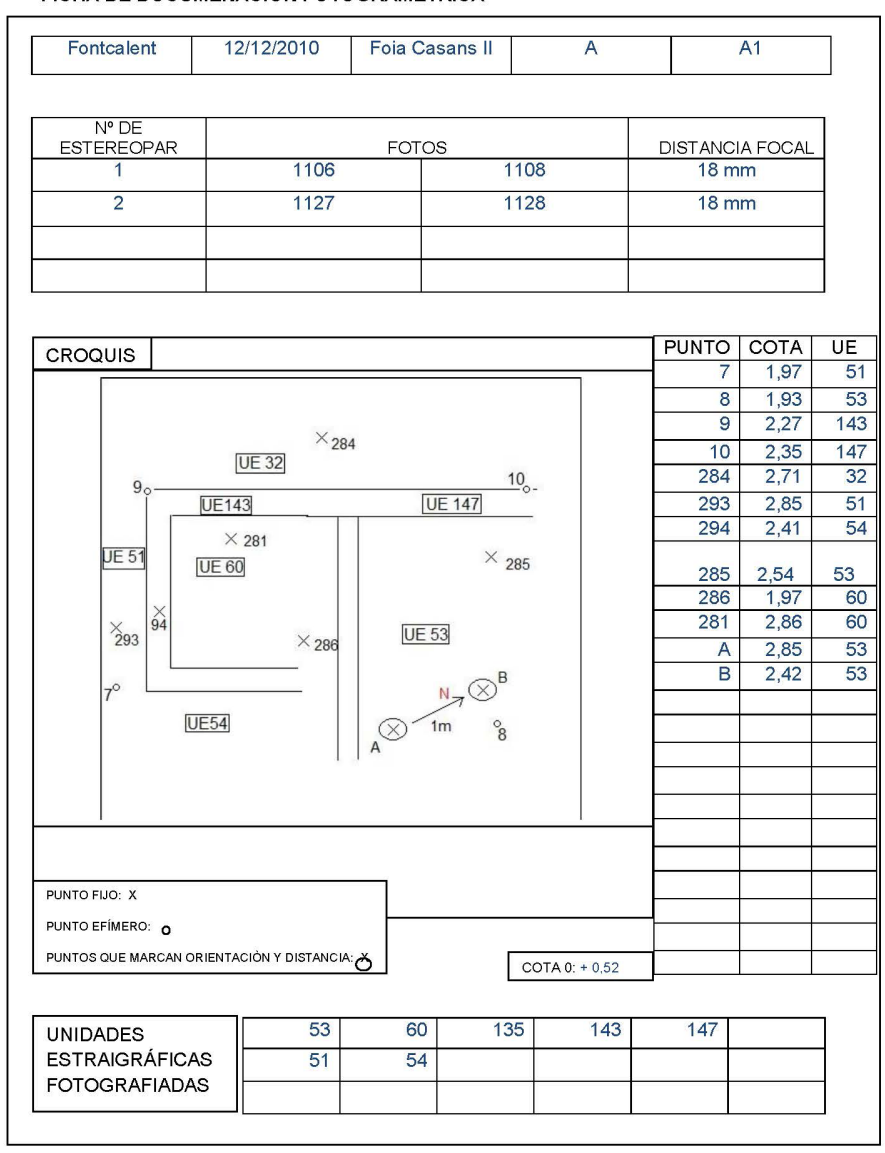

Figura 4.4.1 Propuesta de ficha fotogramétrica, rellenada a modo de ejemplo.

105

Fig. 5. Ficha propuesta para recoger los datos de la documentación fotogramétrica en campo.

La numeración de cada ficha habrá de servir para relacionarlas con las fichas arqueológicas de los estratos documentados, a las que podrán adjuntarse. El objetivo es que la información topográfica, fotogramétrica y arqueológica quede recogida y referenciada de forma que se pueda restituir espacialmente la excavación dentro del sistema de coordenadas en que se encuentre. 


\subsection{Ejemplo de una documentación tridimensional íntegra: la intervención de Lo Boligni (Alicante)}

La intervención de Lo Boligni² (Alicante) sirvió para llevar a la práctica, de forma experimental, nuestra propuesta de documentación íntegramente tridimensional, siguiendo el protocolo y las fichas propuestas (Charquero y Lillo, 2010).

Lasherramientasconlasquerealizamos esta prueba fueron una estación total, una pértiga para elevar una Canon EOS $1000 D$ y el software de fotogrametría Photomodeler Scanner. Dado que el objetivo era excavar el contenido de unas estructuras de combustión dispersas, ya localizadas, dividimos de forma artificial el área en cuadrantes de $3 \times 3 \mathrm{~m}$, marcados por piquetas que habrían de servir de soporte para los puntos de control fijos y que quedarían como único testigo.

El procedimiento para documentar cada superficie de estrato consistía en, en primer lugar, realizar las fotos con pértiga para la restitución fotogramétrica, en segundo lugar rellenar la ficha fotogramétrica anotando las cotas de los puntos efímeros colocados sobre el estrato y dibujar su ubicación en el croquis. Y en tercer lugar, en retirar estos puntos de control efímeros y continuar con la excavación hasta alcanzar el siguiente cambio estratigráfico con el que repetir el proceso (Fig. 6).

Además de la comodidad y fácil integración de esta forma de documentación, ésta nos proporcionó un buen volumen de información detallada; a la información topográfica que reproducía en 3D la ubicación de

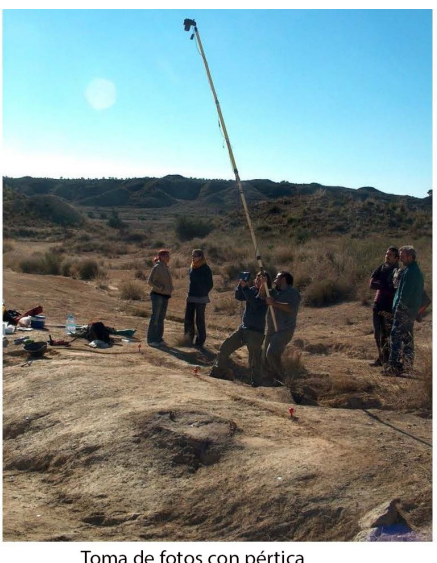

Toma de fotos con pértica

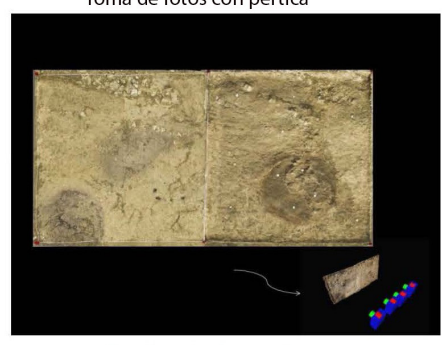

Ortofoto de dos cuadrantes
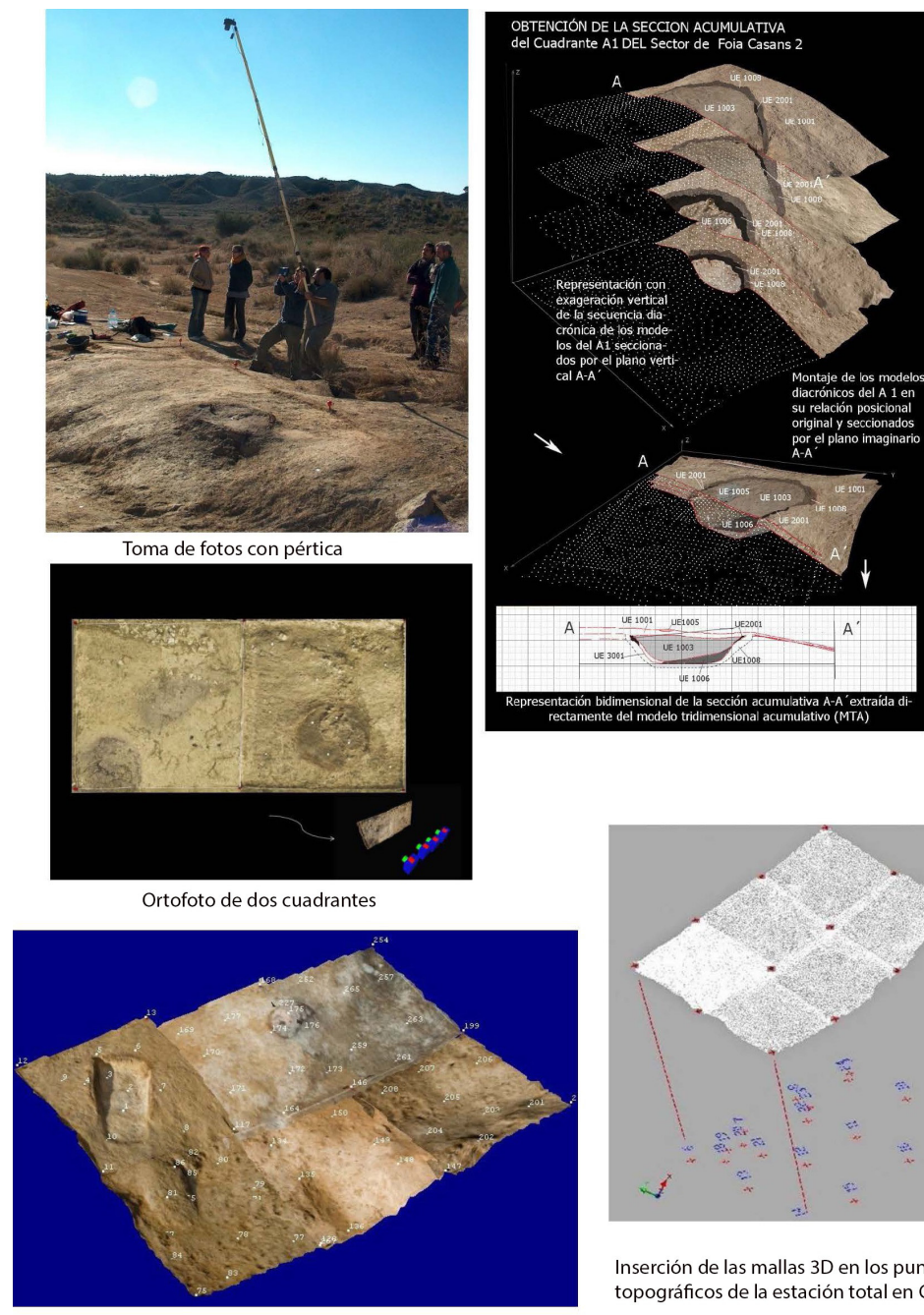

Restitucion horizonal de los cuadrantes de 3×3m

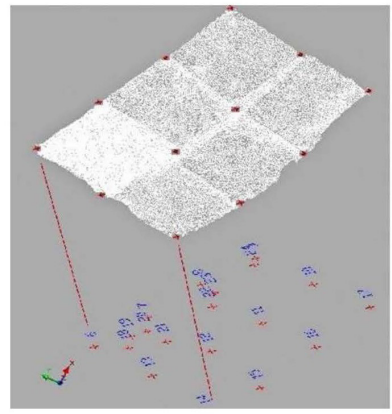

Inserción de las mallas 3D en los puntos topográficos de la estación total en Cad

Fig. 6. Imágenes del proceso y de los resultados de una documetación integral de la estratigrafía mediante fotogrametría.

los puntos fijos y de los efímeros de cada estrato, y por tanto, la estructura tridimensional de la estratigrafía excavada y desaparecida, hay que añadir que contábamos con las fotografías de cada superficie de estrato que nos permitirían restituir el modelo 3D y la ortofoto de cada uno de ellos (Fig. 7). La mayor dificultad fue encontrar un software en el que pudiéramos gestionar conjuntamente la información topográfica y fotogramétrica. La inserción de los modelos 3D en los puntos fijos

2 La intervención de Lo Boligni (Alicante) formaba parte de un proyecto de investigación subvencionado por una ayuda a la investigación del Instituto Alicantino de Cultura Juan Gil-Albert, que tenía por objeto el estudio del proceso productivo de unos hornos dispersos por el campo de alicante. 
topografiados la realizamos en AutoCad 3D, que únicamente permitió importar las mallas 3D sin texturas y cuyo manejo fue muy poco fluido. Tanto a nivel de información extraíble -ortofotos a distintas escalas y secciones (acumulativas) de cualquier plano vertical- como a nivel de trabajo en campo, los resultados fueron realmente satisfactorios. Es en el análisis y la gestión conjunta de datos topográficos y fotogramétricos donde vemos una posible vía de investigación que permita agilizar esta parte tan importante del proceso.

\subsection{Conclusiones acerca de su aplicación en excavaciones}

Tras la aplicación de esta herramienta documental al ámbito de la intervención arqueológica propiamente dicha, extraemos las siguientes conclusiones:

En cuanto a la calidad del contenido informativo, podemos afirmar que la fotogrametría proporciona de forma automatizada una información con calidad métrica precisa, objetiva y sujeta a reelaboraciones posteriores. El potencial analítico que la documentación fotogramétrica ofrece, tiene un gran potencial analítico derivado de su carácter tridimensional. Al asignarle a una nube de puntos tridimensional la información topográfica, cada punto queda insertado en un sistema de coordenadas conocido, dentro del cual, adquirirá unos valores de posición tridimensional determinados, lo que equivale a decir que conoceremos la cota de cada punto de la nube. Por otra parte, al poder obtener secciones de los modelos 3D por cualquier plano vertical, las posibilidades de extraer secciones acumulativas por nuevos planos no planteados durante la intervención, se multiplican considerablemente. Ante el argumento de que la representación de la estratigrafía ha de ser necesariamente simbólica y esquemática para ser funcional, exponemos la respuesta de que lo que aquí se propone no es más que una base documental tridimensional que ha de funcionar como fuente de la que extraer datos para su elaboración. Además, la interoperabilidad que presentan los productos fotogramétricos digitales permiten unas posibilidades de edición, gestión y análisis de los mismos, muy versátiles.

A nivel metodológico, la fotogrametría resulta ser una herramienta muy apropiada para documentar superficies, por lo que se acomoda perfectamente no sólo al método Harris de registro, sino que encaja cómodamente con la herramienta topográfica, complementándose la una con la otra en el contenido informativo y en el proceso de trabajo. En campo, el equipo fotogramétrico resulta ágil y versátil, encontrando como hándicap la excesiva dependencia del proceso de las condiciones de luz, incontrolables en exteriores y, quizás, el que sea una herramienta que requiera cierto tiempo de ejercitación práctica.

A nivel conceptual, la documentación fotogramétrica tridimensional permite un análisis más sofisticado de la estratigrafía a partir de una representación visualmente más comprensible y más cercana a la compleja y sofisticada realidad que está registrando. Carandini afirmaba que la excavación era un largo y arduo proceso y que sólo la documentación analítica de las unidades estratigráficas y su recomposición en la reconstrucción ideal podían reparar el daño de la destrucción que aquélla inevitablemente conllevaba. Añadía que el consuelo era que la excavación traducía forzada e irreversiblemente la pesadez de los materiales y de la tierra en la ligereza de las palabras, los dibujos y de las fotografías (Carandini, 1997, p. 19), y a partir de ahora, quizás también, en la ligereza de los modelos virtuales.

\section{OTRAS APLICACIONES ARQUEOLÓGICAS}

Además de la documentación de estratigrafías arqueológicas, en este trabajo también estudiamos otras aplicaciones de la fotogrametría a otros elementos del ámbito arqueológico y empleamos en ese momento el software Photomodeler Scanner. 
La primera aplicación lógica fue la documentación 3D de piezas escultóricas y arquitectónicas. Como ejemplo de fragmentos arquitectónicos documentamos un fragmento de terracota ornamental itálica, una base de columna romana con restos de estuco y una inscripción romana ${ }^{3}$ (LLidó y Molina, 2012, p. 78). Eran piezas todas procedentes de la intervención arqueológica de Villa de Rufio en Giano dell Umbria., Italia. Como ejemplo de pieza escultórica elegimos el torso del guerrero de la Alcudia de Elche (Alicante) (Fig.7).
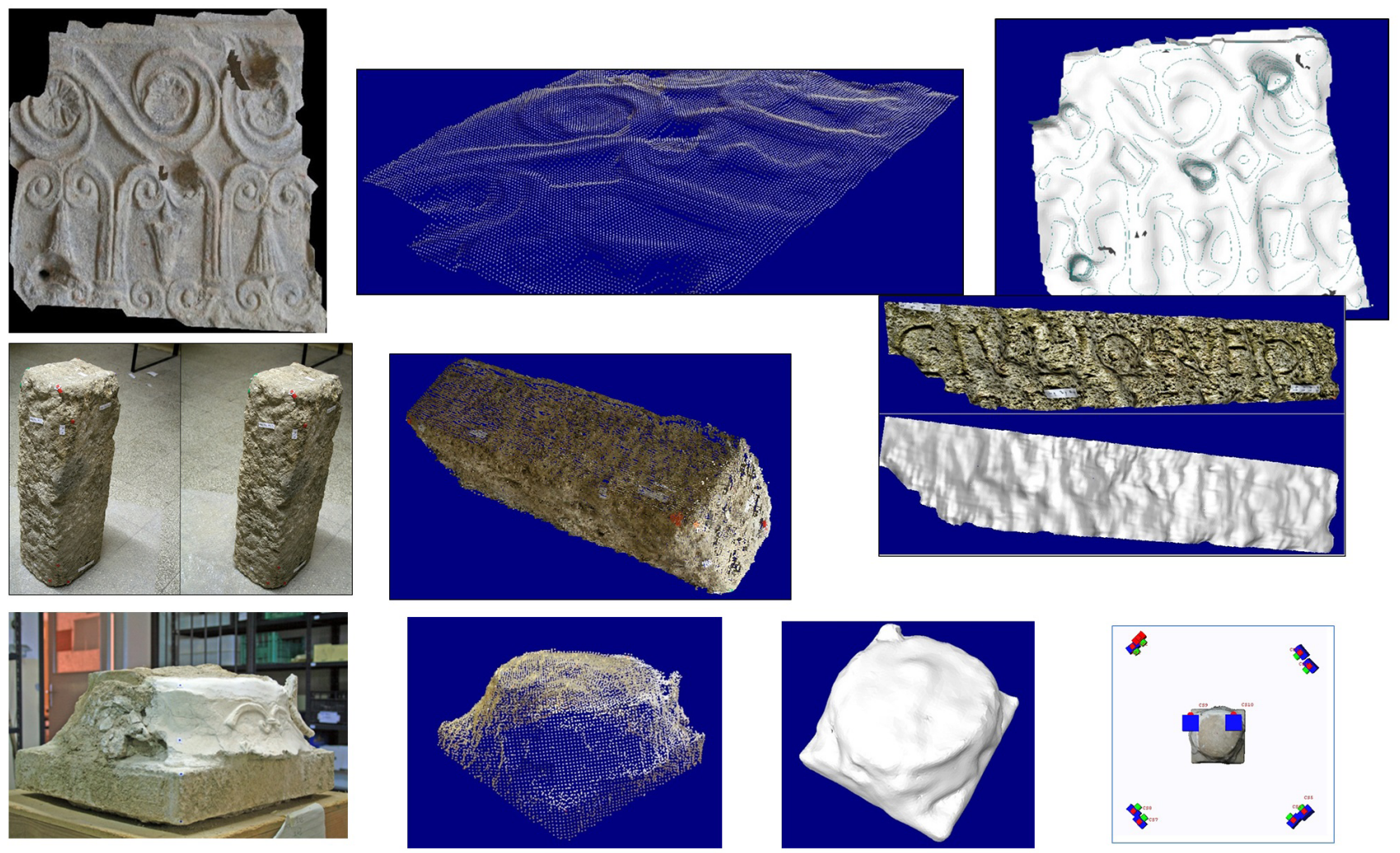

Aplique arquitectónico, incripción y basa de columna con restos de estuco de Villa de Rufio (Giano dell Umbria, Italia)
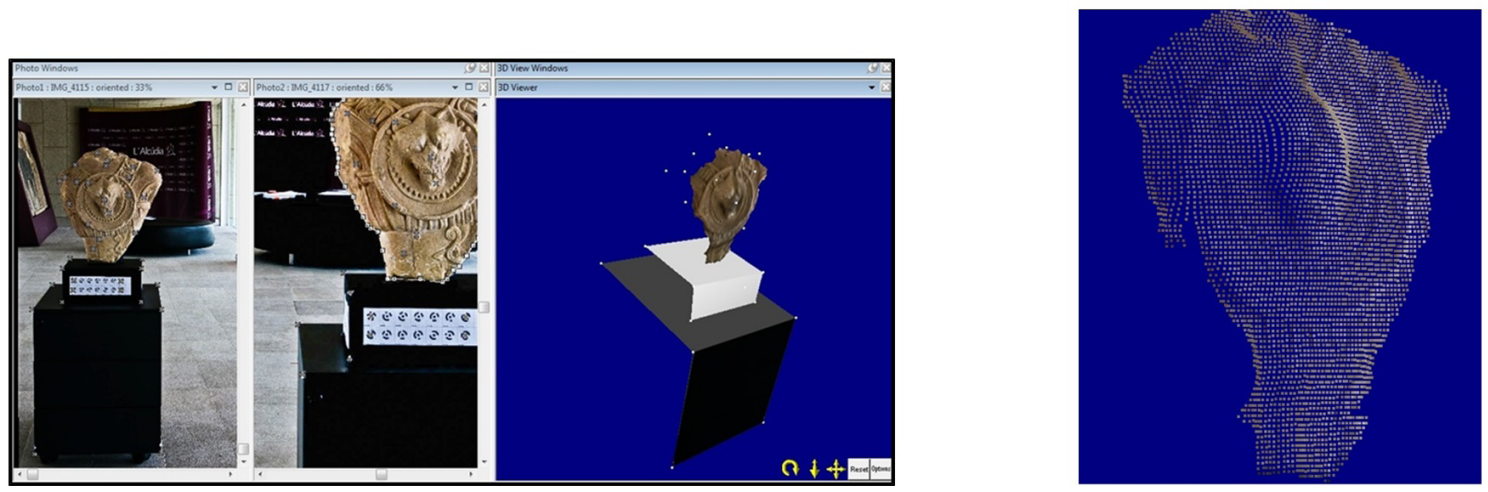

Documentación del torso del guerrero de la Alcudia de Elche (Alicante) con Photomodeler Scanner en 2010

Fig. 7. Documentación de elementos arquitectónicos y escultóricos realizados como ejemplo de la aplicación de la fotogrametría a esta parte del patrimonio arqueológico.

3 La inscripción hallada en este mismo yacimiento que en la que se reconoce/ reconocía la pertenencia de dicha villa a un personaje llamado Caius Iulius Rufio, en la que se podía leer “C (aio) Iulio Rufioni/Nobilis (posuit)” (LLidó y Molina, 2012, p.78). 
A pesar de que la documentación de piezas aisladas resultó ser la aplicación más difícil a nivel de realización - además de ser la primera con la que empezamos a conocer la herramienta fotogramétricanos encontramos ante un método de registro no invasivo que permitiría obtener copias virtuales de calidad que podrían permitir que distintos profesionales se acercaran a la pieza sin necesidad de trasladar físicamente la original. Recientemente ha surgido una nueva aplicación en este ámbito que permite restituir digitalmente piezas escultóricas desaparecidas o destruidas a partir de fotografías de archivo de las mismas ${ }^{4}$.

Una de las aplicaciones más prometedoras fue la documentación de restos óseos en excavaciones. Experimentamos con esta aplicación documentando un enterramiento en fosa de un niño de 1012 años de una pequeña necrópolis tardo-romana (siglos IV y VI) aparecido en la Villa romana
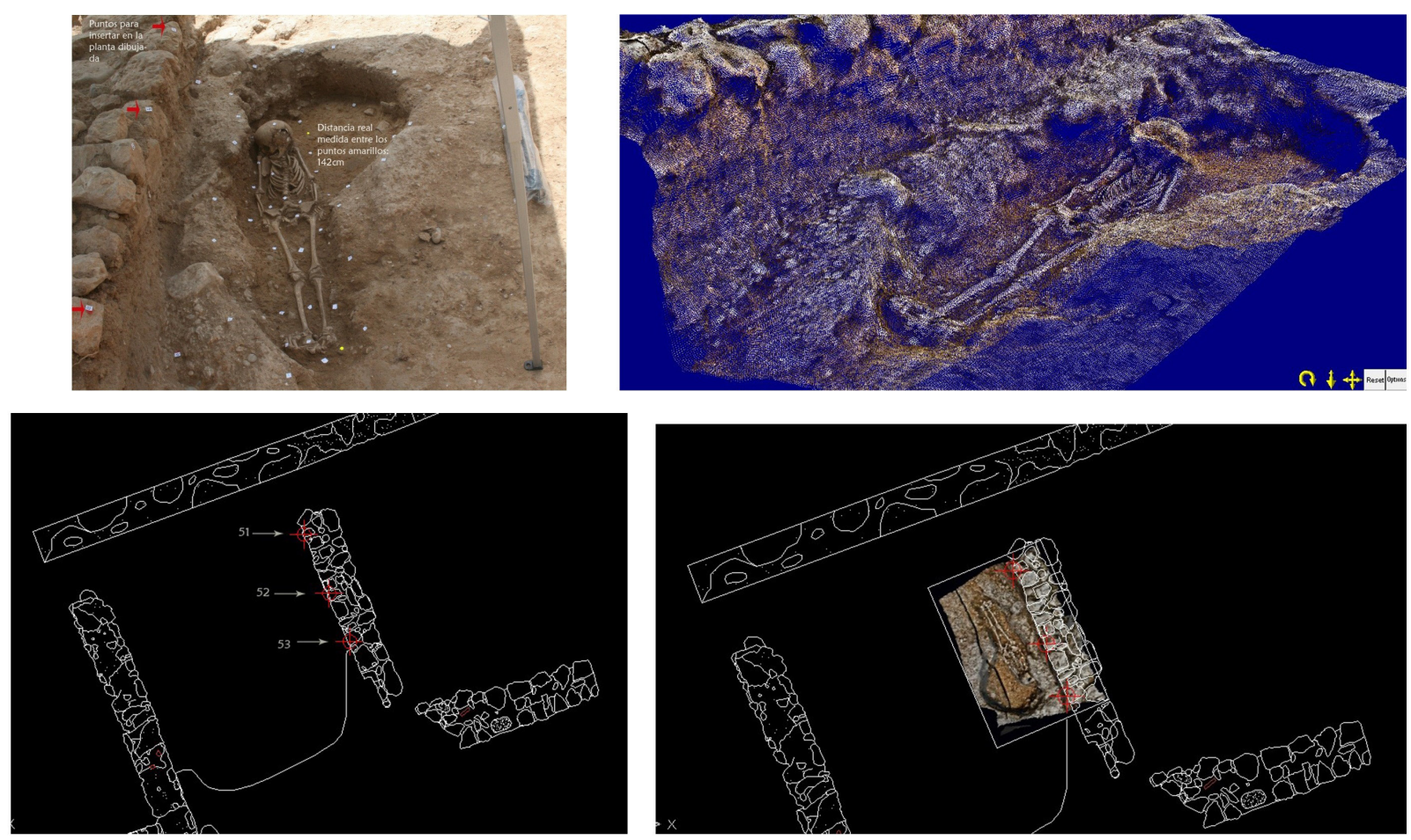

Fig. 8. Documentación experimental de un enterramiento y de la inserción de esta documentación en las planimetrías de AutoCad. Villa romana de L'Albir (L'Alfàs del Pi, Alicante).

de L'Albir (L'Alfàs del Pi, Alicante). La propuesta fue la documentación de enterramientos como entidades aisladas pero con una serie de puntos de anclaje identificables tanto en el modelo 3D como en las planimetrías de las excavación, y con los que posteriormente insertar en estas el dibujo del enterramiento (Fig. 8).

Resulta una aplicación extremadamente eficaz, por cuanto que la reducción de tiempos respecto al dibujo manual es especialmente evidente al tratarse de grandes concentraciones de elementos muy pequeños. Prueba de su eficacia es el uso de la misma -aunque utilizando la tecnología del escáner láser - en yacimientos como el Camino del Molino, en Caravaca de la Cruz (Murcia). Permite además proporcionarle al futuro antropólogo encargado de su estudio una copia virtual 3D del enterramiento, una vez que éste ya ha sido excavado y levantado.

4 http://rhizome.org/editorial/2016/feb/16/morehshin-allahyari/ 
Satisfactoria y con potencial resultó la aplicación de documentación de pinturas rupestres que realizamos en el abrigo con arte levantino de Cuevas Largas II, en el término municipal del Quesa (Valencia) (Martorell y Barciela, 2014). Realizamos una documentación tridimensional con puntos de apoyo a tres escalas (abrigo, paneles y motivos pictóricos) que nos permitieran obtener perfiles del abrigo en los que insertar la ubicación de los paneles y los motivos dentro del mismo, tal y como suele hacerse en la documentación tradicional. Aprovechando la reciente introducción de la estación total en la documentación de arte rupestre (Martínez y Villaverde, 2008), parece ser la ocasión adecuada para introducir el calco digital 3D de motivos pictóricos. Este lo obtuvimos aplicándole en Photoshop un tratamiento que discrimina el pigmento del soporte en función de los tonos de los píxeles, tal y como se viene haciendo sobre fotografías de los motivos. En este caso, una versión extendida de Adobe Photoshop nos permitió realizar esta discriminación en base al color sobre el calco 3D. De esta forma, se mantuvo el formato tridimensional del volumen del soporte, que es un factor más dentro de la intencionalidad del artista al hacer coincidir algunas irregularidades de la roca con ciertas partes de su motivo representado. Teniendo en cuenta las posibilidades documentales que esto supone y que el equipo fotogramétrico resultó ágil en este lugar de difícil acceso, la profundización y experimentación posterior con esta aplicación, parece ineludible (Fig 9).
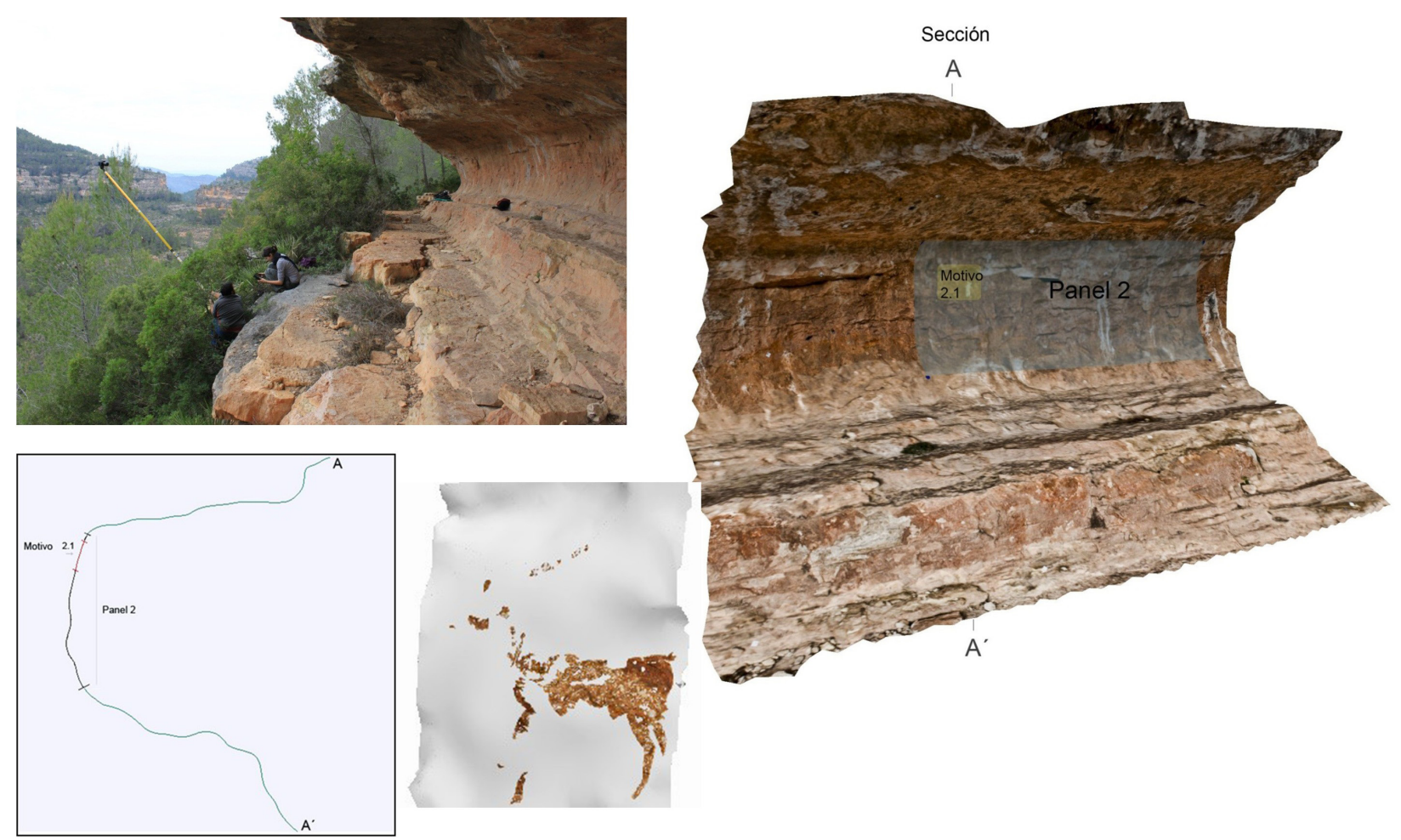

Fig. 9. Documentación experimental de pinturas rupestres mediante calcos 3D en el abrigo de Cuevas Largas II (Quesa), Valencia.

Finalmente, otra de las aplicaciones de la fotogrametría digital es el uso de los modelos tridimensionales de los elementos patrimoniales como soporte sobre el que presentar información arqueológica, ya sea con carácter científico o con fines divulgativos. Supone una forma de representación más intuitiva (Fig. 10). Y aunque no hemos experimentado con ello, porque requiere conocimientos adicionales de modelado y renderización en otros softwares, otra opción que ofrece muchas posibilidades es la de utilizar modelos fotogramétricos tridimensionales como base sobre la que restituir virtualmente las partes faltantes y proponer reconstrucciones virtuales con calidad 


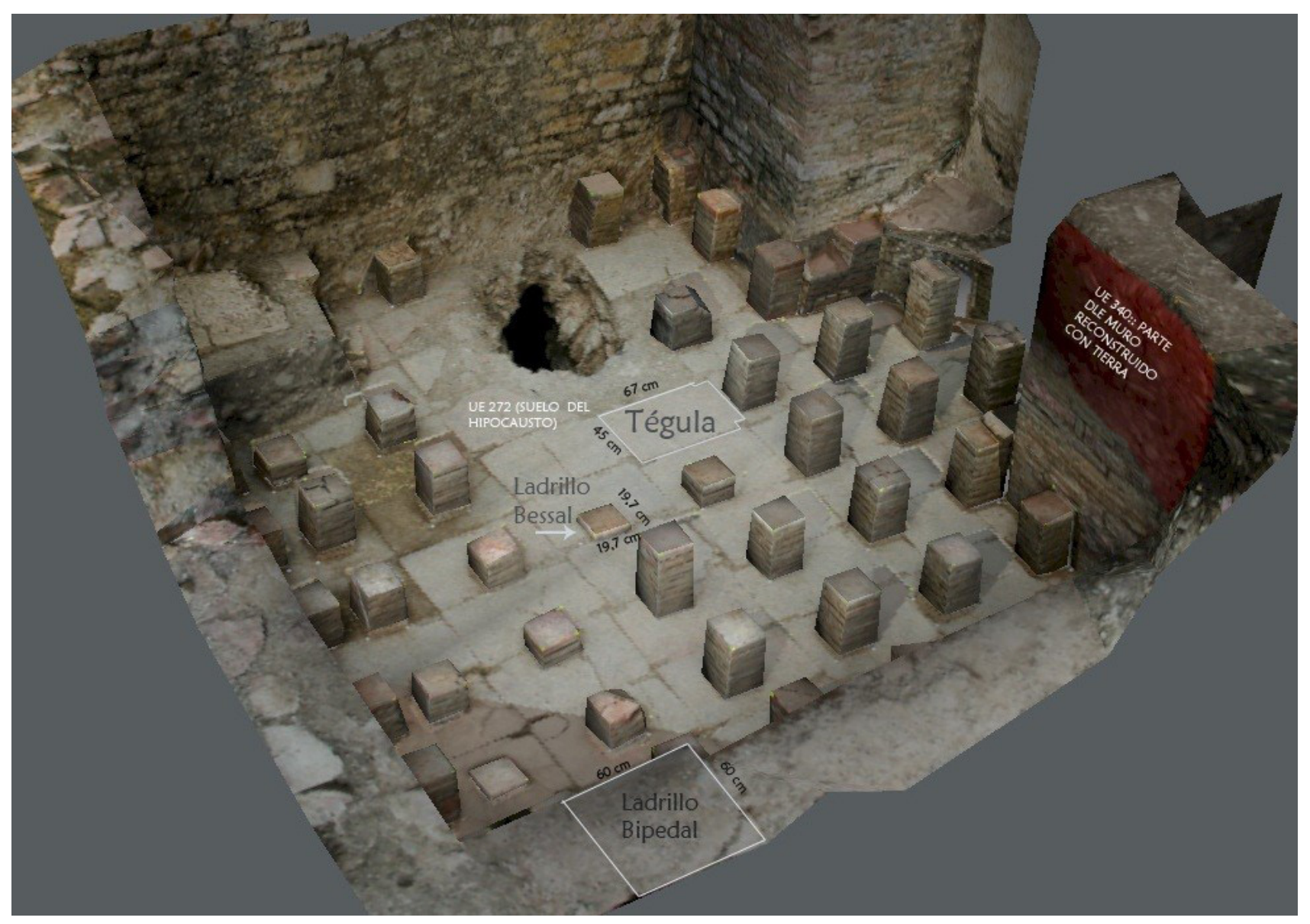

Fig. 10. Propuestas de uso de modelos fotogramétricos 3D como soporte informativo.

métrica. Valga como ejemplo el que se realizó en la Casa de Ariadna de Pompeya (Albiach, Blasco, Escrivá, Molina, Olcina, Ribera, Varea, 2008).

\section{CONCLUSIONES}

Desde muchos puntos de vista, la fotogrametría digital resulta una técnica lo suficientemente completa y eficaz como para suponer un avance importante en la forma de documentar restos arqueológicos. Creemos que lo importante es ir planteando metodologías de trabajo que sigan siendo funcionales a pesar de los avances en el ámbito tecnológico. A pesar de que es un campo de estudio en constante evolución, como decíamos al principio, únicamente llegaremos a ponerlas al servicio de la Arqueología y del Patrimonio si en paralelo a los pasos que estas tecnologías van dando, vamos dando nosotros pasos en las metodologías para aplicarlas. 


\section{BIBLIOGRAFÍA}

Albiach, R., Blasco, J., Escrivà, I., Molina, J., Olcina, M., Rivera, A., Varea, S. (2008). Paseo real y virtual por la Casa di Arianna de Pompeya (VII, 4, 51 Y 53), en Rivera, A., Olcina, M., Ballester, C. (2007). Pompeya bajo Pompeya. (Catálogos de las exposiciones del MARQ), Alicante,

Almagro, A. (2003). De la fotogrametría a la infografía. Un proceso informatizado de información, en García Porras, A. (ed.) Informática y Arqueología medieval, Granada, pp.47-81

Buill, F. Núñez, M.A., Rodríguez, J.J. (2007). Fotogrametría Arquitectónica. Ediciones UPC. Barcelona.

Briz, X. M., \& González, V. B. (2014). El abrigo de Cuevas Largas II (Quesa) en el contexto del arte rupestre postpaleolítico del Macizo del Caroig (Valencia). Recerques del Museu d'Alcoi, (22/23), 27-40.

Caballero Zoreda, L., Arce, F., Feijoo, S. (1996). Fotogrametría y análisis arqueológico. Revista de Arqueología, 186, pp.14-25.

Carandini, A. (1997). Historias en la tierra. Manual de excavación arqueológica. Barcelona. Crítica.

Cattani, M., Fiorini, A., Rondelli, B. (2004). Computer applications for a reconstruction of archaeological stratigraphy as a predictive model in urban and territorial contexts en Ausserer, K.F., Borner, W., Goriany, M., KarlhuberVockl, L. (Eds.), Enter the Past: The E-way into the Four Dimensions of Cultural Heritage. (CAA2003, BAR International Series 1227). Archaeopress, Oxford, pp.299-303.

Charquero Ballester, A., López Lillo, J. (2010). Registro tridimensional acumulativo de la secuencia estratigráfica. Fotogrametría y Sig en la intervención arqueológica de lo Boligni (Alacant) en el III Congreso Internacional de Arqueología e Informática Gráfica, Patrimonio e Innovación, Arqueológica 2.0. Sevilla (Documento científico inédito).
De Reu, J., De Smedt, P., Herremans, D., Van Meirvenne, M., Laloo, P., \& De Clercq, W. (2014). On introducing an image-based 3D reconstruction method in archaeological excavation practice. Journal of Archaeological Science, 41, 251-262.

Grau Mira, I., Molina Vidal, J. (2009). La Villa de Rufio (Giano dell'Umbria, Italia) y su inserción territorial: hipótesis para una investigación combinada (campaña 2008). Universidad de Alicante, Alicante (Documento científico inédito)

Harris, E. C. (1979). Principios de estratigrafía arqueológica. Barcelona. Crítica.

Koistinen, K., Latikka, J., Pöntinen, P. (2001) The cumulative 3D data collection and management during archaeological proyect, en CIPA International Symposium Potsdam, sep. 1821. Institute of Photogrammetry and Remote Sensing. Helsinki. Finland, pp.39-68

López, F. L., \& Vidal, J. M. (2012). Gaius Iulius Rufio propietario en la vía Flaminia, entre Suetonio y la epigafía. Epigraphica: periodico internazionale di epigrafia, (74), 75-82.

Lomba Maurandi, J., López Martínez, M., Ramos Martínez, F., Avilés Fernández, A. (2009) El enterramiento múltiple, calcolítico, de Camino del Molino (Caravaca, Murcia). Metodología y primeros resultados de un yacimiento excepcional." Trabajos de Prehistoria, 66, 2, pp.143-159

Martínez Rubio, T. Y Villaverde Bonilla, V. (2008). Pinturas rupestres de la Cueva del Cerro (Millares, Valencia): una nueva documentación, una nueva lectura. Archivo de Prehistoria Levantina, Vol. XXVII, Valencia, pp.161-179

http://www.agisoft.com/pdf/photoscanpro_1_2_en.pdf(Manual de usuario de Photoscan). 